\title{
Luteinising hormone-releasing hormone nasal spray as therapy for undescended testicle
}

\author{
P. PIRAZZOLI, F. ZAPPULlA, F. BERNARDI, M. P. VILLA, D. ALEKSANDROWICZ, A. \\ SCANDOLA, P. STANCARI, A. CICOGNANI, AND E. CACCIARI
}

From the Paediatric Clinic, University of Bologna, Italy

SUMMARY Twenty-two prepubertal children with unilateral cryptorchidism were treated. None had undergone previous medical or surgical treatment to modify the abnormal position of the testes, all of which were located in the inguinal canal. Treatment was with luteinising hormone-releasing hormone (LH-RH) nasal spray given for 7 days. 9 boys insufflated $100 \mu \mathrm{g}$ LH-RH in each nostril 6 times per 24 hours $(1200 \mu \mathrm{g} / 24 \mathrm{~h})$; the remaining 13 boys insufflated $500 \mu \mathrm{g} 12$-hourly $(1000 \mu \mathrm{g} / 24 \mathrm{~h})$. An LH-RH test (50 $\mu \mathrm{g} \mathrm{IV)} \mathrm{was} \mathrm{carried} \mathrm{out} \mathrm{before} \mathrm{and} \mathrm{after} \mathrm{therapy.} \mathrm{Full} \mathrm{descent} \mathrm{of} \mathrm{the} \mathrm{testis} \mathrm{into} \mathrm{the}$ scrotum was obtained in 7 out of the 22 cases; in a further 6 cases the testis moved down the inguinal canal.

Basal values of luteinising hormone and follicle-stimulating hormone and those for pituitary reserve remained unchanged before and after therapy, and were similar to the values of a control group. No correlation was found between response to therapy and bone age, testosterone level in serum, basal values or pituitary reserve of luteinising hormone or follicle-stimulating hormone.

Luteinising hormone-releasing hormone (LH-RH) therapy in the adult male affected by secondary hypogonadism is known to be effective (Isidori et al., 1974; Mortimer et al., 1974a, b). This releasing hormone, given by nasal spray, was also successfully used in the treatment of adult hypogonadotrophic hypogonadism (Isidori et al., 1974) and cryptorchidism in prepubertal boys (Happ et al., 1975). Since cryptorchidism is sometimes associated with gonadotrophin deficiency (Job et al., 1974; Koch and Rahlf, 1975; Hadziselimovic et al., 1976), we have studied the therapeutic effectiveness of LH-RH in relation to the pituitary reserve of gonadotrophins.

\section{Materials and methods}

Twenty-two boys with unilateral undescended testicle, aged from 5 to $11 \frac{1}{2}$ years, were treated. Bone age ranged from 4 years 10 months to 11 years 4 months and the difference between chronological and bone age never exceeded 6 months. All fell into the prepubertal stage of sexual development, the first stage of Tanner's (1962) classification. None had received previous medical or surgical treatment for testicular maldescent. In all cases the undescended testes were located in the inguinal canal, apparently along the normal descent way; none had retractile testes.

Received 5 August 1977
With permission from the parents, an LH-RH test (50 $\mu \mathrm{g}$ IV) was performed (Cacciari et al., 1976) and treatment with LH-RH nasal spray (Hoechst AG) begun on the next day according to the following schedule. Therapy was given to 9 boys (group A) (mean bone age 7 years 4 months) who insufflated, according to the method of Happ et al., $100 \mu \mathrm{g}$ to each nostril at 7, 8, $12 \mathrm{am}$, and $1,7,8 \mathrm{pm}$, a daily intake of $1200 \mu \mathrm{g} \mathrm{LH}-\mathrm{RH} .13$ boys (group B) (mean bone age 7 years 8 months) received $500 \mu \mathrm{g}$ of the releasing hormone at $8 \mathrm{am}(200 \mu \mathrm{g}$ into the right nostril and $300 \mu \mathrm{g}$ into the left nostril) and at $8 \mathrm{pm}(300 \mu \mathrm{g}$ into the right nostril and $200 \mu \mathrm{g}$ into the left nostril, a daily intake of $1000 \mu \mathrm{g}$ ). LH-RH was given for 7 days, and the day after completing therapy an LH-RH test was repeated.

The pituitary reserve of gonadotrophins was studied by evaluating the peak, the maximum increase, and the area of the curve (Cacciari et al., 1975). Plasma testosterone was recorded before the start of treatment. After the course of LH-RH, those boys whose testes had failed to descend (partially or completely) were given treatment with human chorionic gonadotrophin (HCG) consisting of a weekly injection of 1000 U HCG for 6 weeks.

Bone age was evaluated by the Greulich and Pyle tables (1959). Plasma testosterone was measured by the radioimmunoassay method of Collins et al. 


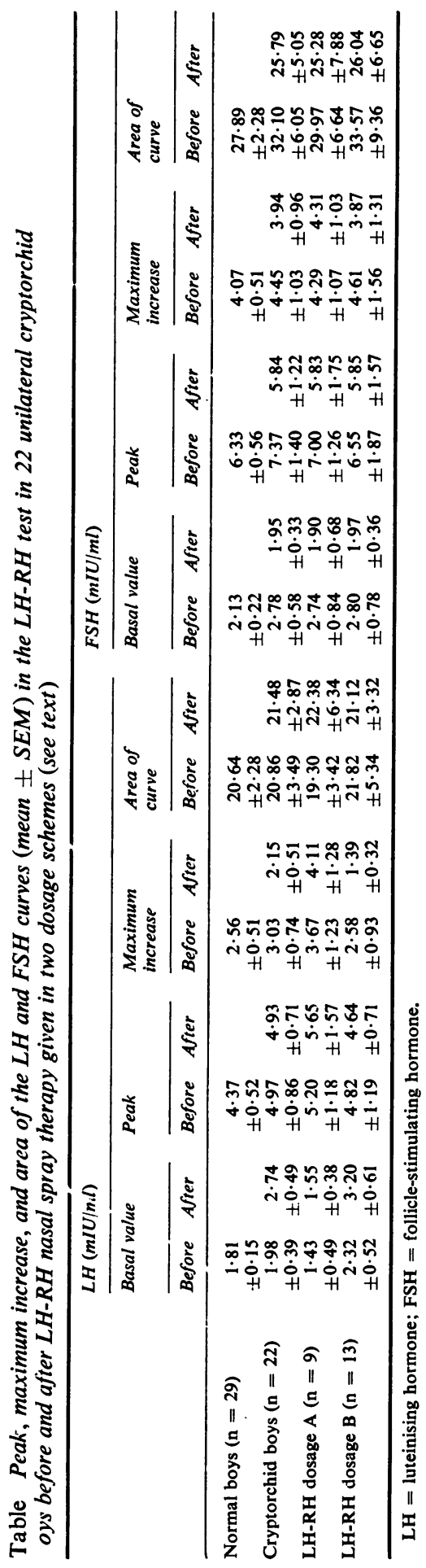


(1972) the antiserum being obtained from rabbits pretreated with an antitubercular vaccine, as previously described (Cacciari et al., 1974). Serum gonadotrophins were measured by the double antibody radioimmunoassay method of Reuter et al. (1973).

For statistical analysis Student's $t$ test was used. In order to study correlations between bone age, basal testosterone, pituitary reserve, and response to therapy, the patients were classified as follows: (1) no response (the position of the testis did not alter); (2) partial response (definite movement down the inguinal canal); and (3) full descent of the testis into the scrotum.

Results from LH-RH tests carried out on 29 short normal boys served as controls.

\section{Results}

Treatment of the 22 cases resulted in $7(32 \%)$ achieving descent of the testis into the scrotum. Of these, $2(22 \%)$ were on dosage scheme $\mathrm{A}$, and 5 $(39 \%)$ on scheme B. In 6 cases $(27 \%), 3$ from each dosage group, the effect on the testicular position was partial. In the remaining 9 cases $(41 \%)$ there was no effect on the testicular position. No difference in the clinical response of the two dosage schemes was observed.

The basal values for luteinising hormone $(\mathrm{LH})$ and follicle-stimulating hormone (FSH) and the pituitary L.H and FSH reserve in the 22 cases did not alter after therapy (Table), and did not differ from those of the control group. No correlation was found between the response to treatment and bone age, basal plasma testosterone level, basal values of LH and FSH, or pituitary reserve of LH and FSH.

Of the 15 boys treated with HCG after LH-RH treatment, one (belonging to the group which had partially responded to LH-RH) achieved complete descent of the testis.

\section{Discussion}

The use of LH-RH nasal spray therapy in cryptorchidism seems capable of producing good results in a short time. The percentage of positive results $(32 \%)$ that we obtained at the end of a week's treatment was higher than that reported by Happ et al. (1975) with a treatment schedule similar to our group A. Those authors continued the therapy for several weeks and obtained a good result in $71 \%$ of cases. Conventional therapy with HCG has given positive results varying from 20 to $90 \%$ (Bader, 1971). So great a variability cannot be due only to the differences in treatment, but must imply that different criteria are used in evaluating cryptorchidism and in differentiating true cryptorchidism from retractile or ectopic testis. We think that we can exclude those cases where the testes were retractile, since the testis could not be brought down into the scrotum despite repeated examinations. On the other hand, we cannot be certain that there was no case of ectopic testis as it is well known how difficult it is to differentiate this.

Our results suggest that the hormone need be administered in only two injections per 24 hours, and that the effectiveness of therapy is independent of age. We found no correlation between response to therapy and bone age or basal testosterone level.

The rationale for treating cryptorchidism with LH-RH nasal spray was the efficacy of such treatment for secondary hypogonadism in the adult (Isidori et al., 1974), and the finding of an LH deficit in a certain number of cryptorchid patients (Koch and Rahlf, 1975; Hadziselimovic et al., 1976; Werder et al., 1976). We therefore expected to find that the response to this form of therapy would correlate with gonadotrophin basal levels and/or gonadotrophin pituitary reserve; and further that this therapy would result in an increase in pituitary reserve and tonic secretion of LH and FSH. However, the response to therapy in our cases did not correlate with the gonadotrophin status either before or after therapy, while the hormone studies carried out before and after the course of therapy failed to show any modification in gonadotrophin secretion as a result of the therapy. We conclude therefore that the efficacy of releasing hormone treatment does not depend on the correction of gross abnormalities of gonadotrophin secretion. It is sufficient to induce repeated small and diminishing stimuli to obtain good therapeutic results in cryptorchidism. The best results were obtained in cases where the undescended testicle was located near the external inguinal ring. No side effects were observed during or after LH-RH nasal spray treatment.

We thank Dr M. Sesso, Farbewerke Hoechst AG, for supplies of synthetic LH-RH, and Alfa Farmaceutici for co-operation in producing antisera.

\section{References}

Bader, J-C. (1971). Les cryptorchidies. Revue du Praticien, 21, 235-257.

Cacciari, E., Cicognani, A., Tassoni, P., Flamigni, P., Bolelli, F., Pirazzoli, P., and Salardi, S. (1974). Plasma testosterone and estradiol concentration in prepubertal boys with cryptorchidism before and after dexamethasone and after human chorionic gonadotropin administration. Helvetica Paediatrica Acta, 29, 27-34.

Cacciari, E., Cicognani, A., Pirazzoli, P., Tassoni, P., Zappulla, F., Salardi, S., and Bernardi, F. (1975). Relationships among the secretion of ACTH, GH, and cortisol 
during the insulin induced hypoglycemia test in the norma and obese child, Journal of Clinical Endocrinology and Metabolism, 40, 802-806.

Cacciari, E., Cicognani, A., Pirazzoli, P., Zappulla, F., Tassoni, P., Bernardi, F., and Salardi, S. (1976). Hypophyso-gonadal function in the cryptorchid child: differences between unilateral and bilateral cryptorchids. Acta Endocrinologica, 83, 182-189.

Collins, W. P., Mansfield, M. D., Alladina, N. S., and Sommerville, I. F. (1972). Radioimmunoassay of plasma testosterone. Journal of Steroid Biochemistry, 3, 333-348.

Greulich, W. W., and Pyle, S. L. (1959). Radiographic Atlas of Skeletal Development of the Hand and Wrist. 2nd ed. Stanford University Press, Stanford, California.

Hadziselimovic, F., Herzog, B., and Girard, J. (1976). Impaired intrauterine gonadotropin secretion as an etiological component of cryptorchidism. (Abst.) Pediatric Research, 10, 883.

Happ, J., Kollmann, F., Krawehl, C., Neubauer, M., and Beyer, J. (1975). Intranasal GnRH therapy of maldescended testes. Hormone and Metabolic Research, 7, 440 441.

Isidori, A., Fraioli, F., and Dondero, F. (1974). International Symposium on Hypothalamic Hormones: chemistry, physiology, pharmacology and clinical uses. October 14 16, Milan.

Job, J-C., Garnier, P. E., Chaussain, J-L., Toublanc, J. E., and Canlorbe, P. (1974). Effect of synthetic luteinizing hormone-releasing hormone on the release of gonadotropins in hypophyso-gonadal disorders of children and adolescents. IV. Undescended testes. Journal of Pediatrics, 84, 371-374.

Koch, H., and Rahlf, G. (1975). Endocrinologic and morphologic investigations in 208 prepuberal, puberal or postpuberal patients with cryptorchidism (Abst.). Acta Endocrinologica, Suppl. 193, 85.

Mortimer, C. H., Besser, G. M., and McNeilly, A. S. (1974a) International Symposium on Hypothalamic Hormones: chemistry, physiology, pharmacology and clinical uses. October 14-16, Milan.

Mortimer, C. H., McNeilly, A. S., Fisher, R. A., Murray, M. A. F., and Besser, G. M. (1974b). Gonadotropinreleasing hormone therapy in hypogonadal males with hypothalamic or pituitary dysfunction. British Medical Journal, 4, 617-621.

Reuter, A. M., Hendrick, J. C., and Franchimont, P. (1973) Mise au point d'un dosage radio-immunologique rapide des gonadotrophines. Annales de Biologie Clinique, 31, 479-487.

Tanner, J. M. (1962). Growth at Adolescence, 2nd ed. Blackwell, Oxford.

Werder, E. A., Illig, R., Torresani, T., Zachmann, M. Baumann, P., Ott, F., and Prader, A. (1976). Gonadal function in young adults after surgical treatment of cryptorchidism. British Medical Journal, 2, 1357-1359.

Correspondence to Professor Emanuele Cacciari, Clinica Pediatrica dell'Università, Via Massarenti 11, 40138 Bologna, Italy. 